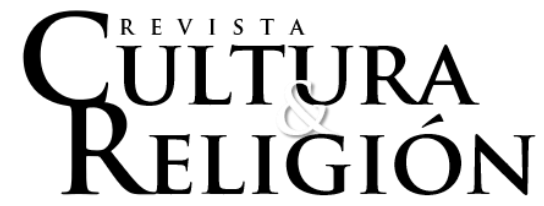

Vol. XV, No 2 (2021) pp. 1-38

Recibido: 16 de marzo de 2021

Aceptado: 16 de agosto de 2021

\title{
DESDE LOS MÁRGENES DE LA SOCIEDAD AL PARLAMENTO. EVANGÉLICOS Y POLÍTICA EN BRASIL, ARGENTINA Y URUGUAY*
}

From the margins of society to parliament. Evangelicals and politics in Brazil, Argentina and Uruguay

\author{
Felipe Arocena** \\ Universidad de la República, Uruguay \\ ORCID: 0000-0002-1666-8449 \\ María Victoria Sotelo ${ }^{* * *}$ \\ Universidad de la República Uruguay, Uruguay \\ ORCID 0000-0001-9756-4862
}

\section{Resumen}

En este trabajo se analiza el avance de las confesiones evangélicas en el escenario religioso latinoamericano y cómo esta progresión se manifiesta en la arena política de tres países. Se abordan las relaciones cambiantes entre evangélicos y política en Brasil, Argentina y Uruguay, y se prueba que, a pesar

* El presente artículo se desarrolló dentro del Programa de Investigación en Sociología de la Cultura del Departamento de Sociología de la Facultad de Ciencias Sociales, Universidad de la República Oriental del Uruguay. En particular, se basa en el proyecto doctoral de Victoria Sotelo, titulado "La presencia de los evangélicos en el escenario político uruguayo del siglo XXI", financiado a través de una beca por la Comisión Académica de Posgrado de la Universidad de la República.

** Doctor en Sociología; Profesor Titular en el Departamento de Sociología de la Facultad de Ciencias Sociales, Universidad de la República, Uruguay; Nivel II del Sistema de Investigadores de Uruguay. Correo electrónico: farocena@ adinet.com.uy

*** Doctoranda en Sociología, Facultad de Ciencias Sociales, Universidad de la República, Uruguay; Docente del Centro Regional de Profesores Suroeste, Administración Nacional de Educación Pública. Correo electrónico: victoria.sotelo@gmail.com 
de las enormes diferencias entre estos, hay claramente similitudes en las agendas políticas que los evangélicos apoyan. En los tres países, los evangélicos han impulsado una agenda provida y profamilia en alianza con los católicos. Se concluye que en Brasil las iglesias evangélicas adoptan candidaturas oficiales ("Políticos de Cristo") que promocionan entre sus fieles y se advierte la presencia simultánea de partidos evangélicos, frentes evangélicos y facciones evangélicas, mientras que en Argentina y en Uruguay los evangélicos poseen una participación dentro de partidos políticos bien establecidos.

Palabras clave: evangélicos, política, Brasil, Argentina, Uruguay.

\begin{abstract}
This article analyzes the progress made by evangelical groups in the Latin American religious context and how this progression manifests in the political arena in three countries. The authors address changing relationships between evangelicals and politics in Brazil, Argentina and Uruguay, showing that there are clear similarities in the policy agendas supported by evangelicals despite the enormous differences between these countries. Evangelicals have promoted a pro-life and pro-family agenda in partnership with Catholics in all three countries. The article concludes that evangelical churches advance official candidates ("Politicians of Christ") in Brazil who are promoted among the faithful and that there is a simultaneous presence of evangelical parties, evangelical fronts and evangelical factions. Meanwhile, evangelicals participate in well-established parties in Argentina and Uruguay.
\end{abstract}

Keywords: Evangelicals, politics, Brazil, Argentina, Uruguay.

\title{
Introducción
}

El propósito de este artículo es analizar la reciente expansión de los evangélicos y cómo esta repercute en el ámbito político de tres países: Brasil, 
Argentina y Uruguay. Creemos que la comparación de estos tres países del Cono Sur es una nueva y relevante contribución a la ya vasta área de investigación sobre los evangélicos en América Latina en su conjunto, o en países individuales, ya que no conocemos trabajos anteriores centrados en esta tríada.

En los últimos cincuenta años, "la cara pública de la religión en América Latina, y en general la presencia de la religión en la esfera pública y en la vida social y política del continente ha experimentado enormes cambios" " (Levine, 2006, p. 7). ${ }^{1}$ En el pasado no tan lejano la cara pública de la religión evocaba una alianza entre la Iglesia católica (se identificaba tan solo una iglesia) y el poder político, económico y social. El debilitamiento del monopolio católico es un proceso a largo plazo que apenas comienza a tomar fuerza. El desafío es generar una nueva agenda de estudios, enfoques y metodologías para comprender "las múltiples consecuencias del pluralismo religioso, tanto para la religión en sí, como para la política y sobre todo para una vida política democrática" (Levine, 2006, p. 27).

Para comprender hoy lo religioso y su vínculo con lo político, lo económico, lo social, lo cultural y lo simbólico en América Latina debemos orientar nuestra mirada a un doble proceso: por un lado, la presencia diversificada de personas, grupos y organizaciones religiosas en diversas esferas de lo público y lo privado; y por otro, las transferencias, legitimidades y dislocaciones mutuas en el espacio que podemos llamar del poder y de eficacia simbólica donde se combina lo político y lo religioso (Mallimaci y Cruz Esquivel, 2013).

Tanto en las calles como en las urnas, los evangélicos han demostrado en América Latina ser la fuerza política más nueva y pujante desde que surgieron los movimientos sociales de los años noventa del siglo pasado. En los debates políticos toman posturas en torno a temas de género, familia y sexualidad, en algunos casos en alianza con los católicos.

\footnotetext{
${ }^{1}$ Ver también Mallimaci (2008), Burity (2008) y Mallimaci y Cruz Esquivel (2013).
} 
En varios países latinoamericanos, los evangélicos se movilizan contra proyectos de ley, en otros tienen sus propios partidos políticos e incluso candidatos presidenciales. El presidente de Guatemala Jimmy Morales es evangélico (férreo opositor del aborto y el matrimonio gay), mientras en México un partido de base evangélica apoyó al presidente Andrés Manuel López Obrador, quien en forma reiterada cita la Biblia y el Evangelio en sus discursos. En Brasil, el apoyo que le brindaron los evangélicos al actual presidente Jair Bolsonaro fue clave para su victoria en los comicios electorales de 2018. Incluso en un país como Costa Rica, sorprendió la adhesión que tuvo el candidato evangélico Fabricio Alvarado. En Venezuela y Colombia, en 2018, se presentaron como candidatos presidenciales dos pastores evangélicos (Javier Bertucci y Jorge Antonio Trujillo, respectivamente). Por tales motivos podemos afirmar que los evangélicos avanzan con contundencia en el mapa de poder de América Latina.

En este artículo intentaremos dar respuesta a las siguientes interrogantes: ¿cuáles son las causales del surgimiento de los evangélicos como actor político-religioso en América Latina, particularmente en Brasil, Argentina y Uruguay? ¿Cuáles son los objetivos de su accionar en el terreno partidario?, ¿en qué políticas públicas buscan incidir?, ¿cuáles son las demandas que han suscitado movilizaciones en las calles protagonizadas por estos actores? ¿En qué medida se cumple el lema "hermano vota a hermano" en los tres países elegidos para este análisis? Para dar respuestas a estas interrogantes, nos referiremos en primer lugar a la metodología utilizada; en segundo lugar, al modelo teórico escogido para la comparación; luego analizaremos la expansión de los evangélicos en la región; y dedicaremos tres apartados a analizar la proyección de los evangélicos en el escenario político de Brasil, Argentina y Uruguay, concluyendo con los elementos en común y las diferencias que se aprecian, en los tres casos escogidos. 


\section{Metodología utilizada}

En este artículo utilizaremos el método comparativo para analizar la participación política de los evangélicos en tres países del Cono Sur (Brasil, Argentina y Uruguay), para dejar de manifiesto que la incursión evangélica en el ámbito político es un fenómeno regional, pero que presenta sus matices según las características del país en el que se desenvuelve. Consideramos que la comparación está implícita en toda actividad cognoscitiva. Cuando planteamos nuevas hipótesis en ciencias sociales y elaboramos nuevas explicaciones de un fenómeno concreto, la comparación nos permite alcanzar resultados de gran relevancia. Como señala Morlino (1994), "sólo la comparación nos permite defender una hipótesis más que otra, gracias al control de más casos" (p. 14).

Realizaremos una comparación sincrónica y diacrónica de la participación política de los evangélicos en Brasil, Argentina y Uruguay. Nuestra intención es efectuar una “comparación globalizadora” (Tilly, 1991, p. 177), ya que se explicarán casos específicos como resultados de lógicas sistémicas globales.

Tomando en cuenta los antecedentes de investigación de Sotelo (2010a, 2010b, 2012, 2020), en los que se demuestra que las religiones neopentecostales se expanden en contextos de mayor pobreza y exclusión en nuestra región, brindando en muchos casos servicios de asistencia social, someteremos a prueba la hipótesis que sostiene que esa intervención social que realizan las iglesias evangélicas en los contextos de mayor pobreza y exclusión, genera una fidelidad que tiene luego un correlato en las urnas. El discurso religioso neopentecostal atrae a las capas más desfavorecidas de la sociedad, principalmente a través de lo que se ha denominado "la teología de la prosperidad", en la que a través del diezmo y la ofrenda los fieles buscan un ascenso social cuando ven frustradas las vías de acceso habituales para lograrlo.

Para analizar el caso uruguayo, nos basaremos en los hallazgos de 14 entrevistas en profundidad realizadas por Victoria Sotelo para su trabajo doctoral y en la bibliografía de los principales exponentes de las ciencias 
sociales de la religión del país, mientras que para el caso argentino y el brasilero únicamente nos basaremos en una revisión bibliográfica sobre el tema. Para cuantificar el número de evangélicos y su evolución a lo largo del tiempo realizaremos un análisis de datos secundarios proporcionados por Latinobarómetro, tanto a nivel diacrónico en una serie de tiempo, como a nivel sincrónico.

\section{Modelo teórico para la comparación}

Para la comparación teórica, utilizaremos la tipología elaborada por Pérez Guadalupe (2019, pp. 80-82), que propone tres modelos de participación política de los evangélicos, a saber:

1) El partido evangélico: "movimiento o partido confesional, integrado y liderado exclusivamente por 'hermanos evangélicos'" (Pérez Guadalupe, 2019, p. 80).

2) El frente evangélico: "se trata de un frente político liderado por hermanos evangélicos de diferentes denominaciones, pero que abre a otros actores que comparten con ellos sus ideales políticos" (Pérez Guadalupe, 2019, p. 81).

3) La facción evangélica: "consiste en la participación de líderes evangélicos en procesos electorales dentro de partidos o movimientos políticos ya constituidos" (Pérez Guadalupe, 2019, p. 82).

Tomaremos en cuenta los siguientes elementos para analizar la proyección partidaria evangélica en los distintos países: a) el sistema político de cada país; b) el peso político, social y religioso de la Iglesia católica; y c) la cultura política de cada país.

\section{La expansión de los evangélicos en la región}

En América Latina, la región de donde proviene el actual papa Francisco (el argentino Jorge Mario Bergoglio), el 59 \% de la población se define como 
católica, según datos publicados por Latinobarómetro en 2018. El porcentaje de católicos en 1996 llegaba al 80 \% de la población latinoamericana; es decir, se observa un descenso de 21 puntos porcentuales de católicos en el lapso de dos décadas. Una verdadera revolución cultural en un lapso cortísimo. Esta revolución cultural se llama evangelismo. Hoy quienes profesan el cristianismo evangélico son uno de cada cinco latinoamericanos: el $20 \%$. Según Latinobarómetro (2018), los evangélicos representan en cada país los siguientes porcentajes de su población: Argentina (12\%), Bolivia (17\%), Brasil (26\%), Chile (14 \%), Colombia (15\%), Costa Rica (28 \%), República Dominicana (22 $\%$ ), Ecuador (16\%), El Salvador (29\%), Guatemala (40\%), Honduras (44 \%), México (2\%), Nicaragua (35\%), Panamá (31\%), Paraguay (7\%), Perú (18 $\%)$, Uruguay (7\%), Venezuela (18\%).

Gráfico $\mathbf{N}^{\circ} 1$ : Porcentaje de evangélicos en América Latina (2018)

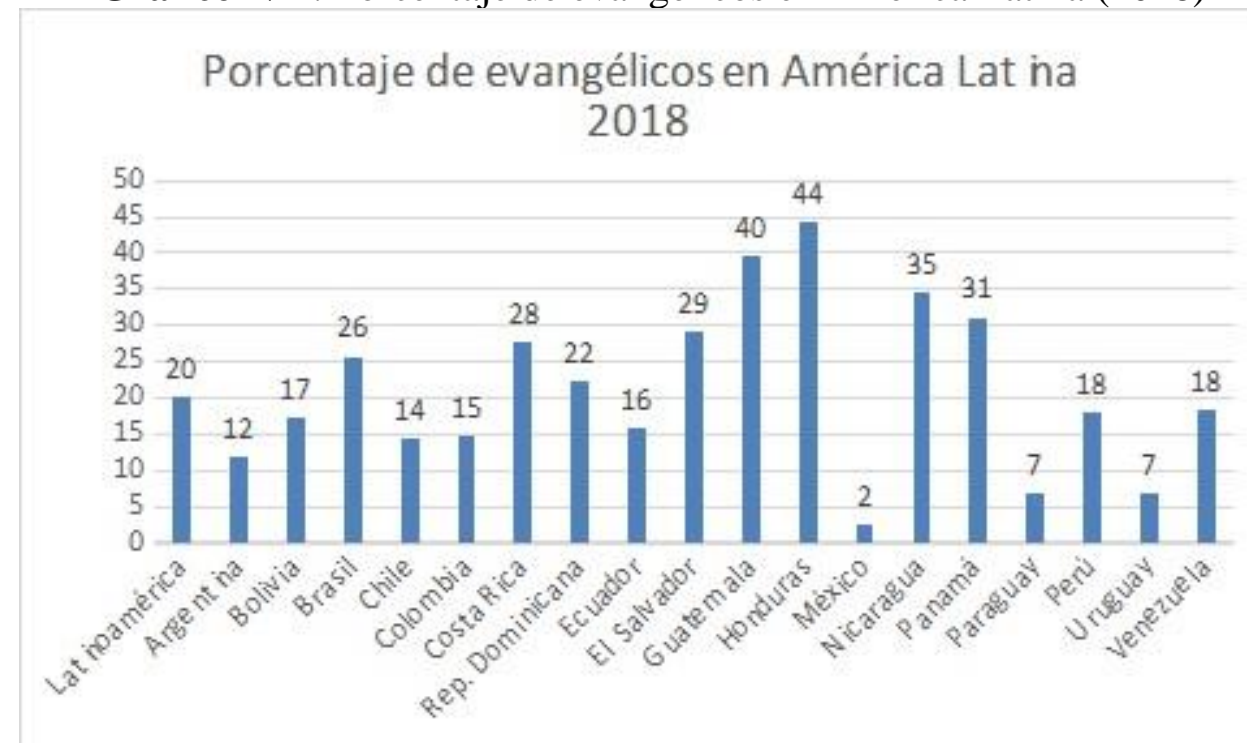

Fuente: elaboración propia en base a Latinobarómetro 2018

En varios países latinoamericanos (Argentina, México, Perú, Chile, Costa Rica, Colombia), los evangélicos se han manifestado en marchas contra el aborto, contrarios al matrimonio gay y en defensa de la familia tradicional, en alianza con los católicos. Incluso hay estudios que muestran el accionar 
conjunto de los evangélicos en la región en organismos multilaterales como la OEA (Panotto, 2020). Vemos de todas maneras que este conservadurismo religioso choca contra una inmensa cantidad de latinoamericanos que se definen como "no creyentes": el 16 \%, según Latinobarómetro (2018), cifra que viene creciendo desde 1995 (como se observa el gráfico $\mathrm{N}^{\circ}$ 2).

Eso hace que estemos ante un escenario muy polarizado en la región, donde también se evidencian manifestaciones de ciudadanos que reclaman la laicidad del estado, al no compartir las posturas religiosas de estos grupos en temas de familia, género o reproducción.

Gráfico N²: Evolución de la adscripción religiosa en América Latina (1995-2018)

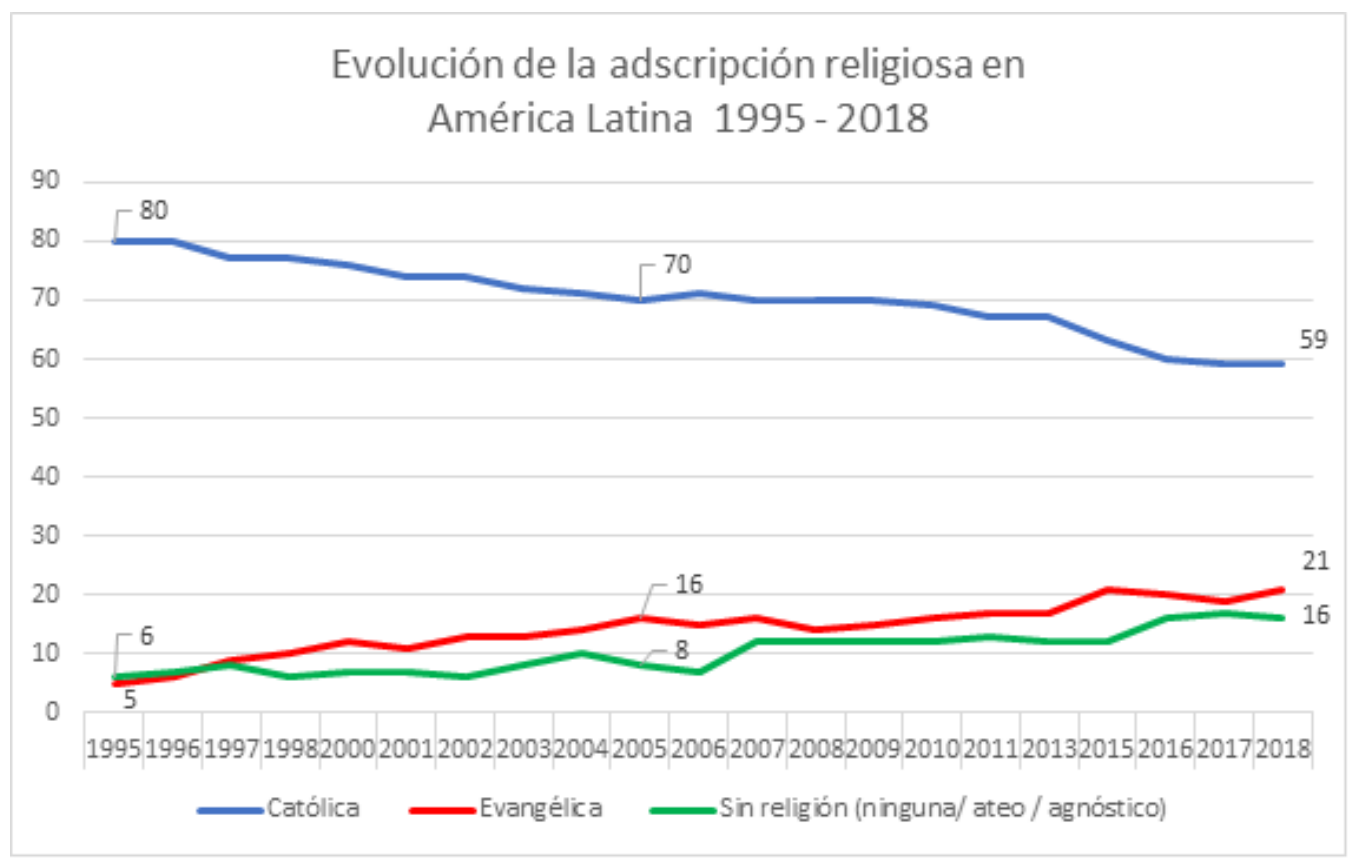

Fuente: elaboración propia en base a Latinobarómetro 2018

Freston (2012) enfatiza que los cambios religiosos en América Latina se deben a la conversión; son cambios "desde adentro" (no es debido a la actuación de misioneros extranjeros, ni por inmigrantes) y "desde abajo" (no 
ocurren por una reforma nacional). Es por ello que las transformaciones en la relación entre religión y Estado (y política) son muy complejas.

En consecuencia, la región difiere claramente de Europa, donde el nuevo pluralismo religioso resulta de la inmigración y de la secularización, con implicaciones para los debates sobre la incorporación de la diversidad religiosa en la esfera pública. Hay una diferencia fundamental (en cuanto a las implicaciones culturales y políticas) entre globalización diaspórica y globalización conversionista. En este sentido, el pentecostalismo es vital como motor de los cambios religiosos y religioso-políticos. Es el pentecostalismo que estructura el modelo emergente del campo religioso, un modelo que incluye muchos otros actores, pero del cual los pentecostales han sido los principales creadores. Eso, en varios sentidos. Primero, por su mismo éxito numérico: en toda la región, el pentecostalismo ya es la segunda fuerza religiosa, con excepción de Uruguay, donde es ultrapasado por los 'sin religión'. En segundo lugar, por su efecto en 'pentecostalizar' otros sectores del campo religioso (sea por la imitación como en la Renovación Carismática Católica, o por las reacciones hostiles que llevan a modificaciones en las religiones rivales). (Freston, 2012, p. 82).

No obstante, para el autor la transición protestante en América Latina tendrá un techo, ya que hay un núcleo duro de católicos que no se va a erosionar, pues el catolicismo va modificando sus estrategias y ha aprendido a competir mejor. Por otro lado, la imagen evangélica a veces está cargada de visiones negativas, escándalos, imágenes autoritarias, promesas incumplidas, etc. Es por ello que Freston vaticinaba hace ya ocho años que la transición protestante en América Latina alcanzará -en algunos países antes que en otrosun estancamiento y una posterior caída.

En contra de esta hipótesis, nuestro trabajo muestra que ese techo claramente no se alcanzó y, por el contrario, cada vez se ve más alto en prácticamente todos los países latinoamericanos. Como anticipamos al comienzo, la transformación religiosa latinoamericana ha de verse como uno de 
los cambios culturales más vertiginosos en toda la región. La rapidez y el alcance de este cambio

social se ve reflejado en nuevas relaciones entre religión y política, tal como veremos a continuación.

El campo evangélico se compone de los herederos de diferentes grupos religiosos del cisma del siglo XVI: luteranos, metodistas, calvinistas, bautistas, menonitas, presbiterianos y pentecostales, entre otros. Por tanto, cuando utilizamos el término "evangélicos" lo hacemos de una manera genérica para denominar a los grupos vinculados de diversas maneras a la reforma protestante. Los pentecostales son la rama evangélica que más ha crecido en el siglo XX en todo el mundo y es la que ha logrado mayor incidencia en el escenario político contemporáneo. Por tanto, consideramos que hay que partir del supuesto de que no se puede caracterizar al universo evangélico como un todo homogéneo y monolítico, sin distinguir la pluralidad de ideas y accionar dentro de los distintos colectivos que lo componen. El protestantismo, antecedente de todas las iglesias evangélicas, es un movimiento cristiano que basa la autoridad religiosa en la Biblia y se opone a la infalibilidad del papa. Ser evangélico no implica estar registrado en una burocracia, consiste en un encuentro personal con Jesús, el Espíritu Santo y Dios Padre (Semán, 2019).

Hay tres tendencias evangélicas en América Latina: i) protestantismos históricos (llegaron a la región en el siglo XIX y se limitaron a comunidades migrantes): luteranos, metodistas, valdenses y calvinistas; ii) tendencias evangelicales (originadas en Estados Unidos, llegadas a América Latina desde principios del siglo XX, con sentido misionero y proselitista): iglesias bautista, presbiteriana y Hermanos Libres; iii) los pentecostales, quienes sustentan la actualidad de los dones del Espíritu Santo (nacieron a principios del siglo XX, en los episodios acaecidos en la Calle Azusa, Iglesia Episcopal Metodista Africana de California en 1906, donde ocurrieron eventos similares a los de Pentecostés).

El neopentecostalismo -que nace a finales de la década de 1960 y principios de la de 1970- exacerba las características del pentecostalismo 
(milagros, el papel de los pastores) y dos articulaciones teológicas claves: la “teología de la prosperidad" y la "guerra espiritual” (Semán, 2001, 2019, pp. 31-32). Los evangélicos históricos han tenido en el pasado una contribución crucial al campo de la defensa de los derechos humanos. Ese terreno ganado en la arena política por los evangélicos históricos es ocupado en la actualidad por los pentecostales (y neopentecostales).

El crecimiento de los evangélicos pentecostales y neopentecostales en toda América Latina desde la década de 1980 está vinculado a "una resurrección espiritual conservadora, reaccionaria, cuasi fundamentalista de la 'nueva derecha' o 'mayoría moral' en Estados Unidos, que surge en 1974, y desde allí, e inicialmente con Ronald Reagan, sustenta las derechas político ideológicas estadounidenses por el mundo" (Bayce, 2 de julio de 2017, s. p.). Desde 1913, el presidente Roosevelt señalaba que sería difícil la absorción de los países latinoamericanos mientras fuesen católicos. ${ }^{2}$ El Informe Rockefeller (1970) subraya que América Latina había dejado de ser confiable en términos religiosos porque las Comunidades Eclesiales de Base (CEB) en Brasil y la teología de la liberación en toda Sudamérica lideraban radicalmente a las masas y colectivos sociales, entre otras tendencias menos agresivas en otros países, como Chile y Uruguay. Sin embargo, el crecimiento de las iglesias pentecostales no solo se explica por la trilogía de conservadurismos religiosos (protestante, católico y judío) que comanda en Estados Unidos hace casi cuarenta años, sino también se debe tener en cuenta que dichas creencias resultan atractivas para las clases medias amenazadas de movilidad descendente y las que no acceden al paquete de bienes y servicios que el Estado mengua.

En las tres secciones siguientes se analiza el impacto del crecimiento demográfico pentecostal en el escenario político de Brasil, Argentina y Uruguay.

\footnotetext{
2 Para ver un ejemplo de la oposición más histórica entre católicos y evangélicos en América Latina, ver el análisis de Escobar y Nuñéz (2020) en el sur de Chile.
} 


\section{El poder evangélico en la política de Brasil}

Los evangélicos tienen una bancada con decenas de parlamentarios en el Congreso brasileño y un pastor que ocupa el cargo de alcalde de Río de Janeiro. Bolsonaro alcanzó la presidencia con el apoyo de los evangélicos; también Lula tuvo como vicepresidente cuando ganó su primera elección a un evangélico como José Alencar. A pesar de definirse como católico, Bolsonaro fue bautizado por un pastor evangélico en el río Jordan, en Israel, en 2016, en lo que muchos consideran fue su primer acto de campaña. Él mantiene esa "productiva ambigüedad religiosa", se hizo evangélico sin dejar de ser católico, y es el primer presidente que posee un discurso abiertamente pentecostal (Oualalou, 2019). Lo anterior se pudo evidenciar en su primer discurso luego de su victoria, cuando puso explícitamente su mandato bajo la supervisión de Dios, recordando el slogan de su campaña: "Brasil por encima de todo, Dios por encima de todos" (Oualalou, 2019, p. 69).

En 1970, el $92 \%$ de los brasileños se declaraba católico, mientras que en 2010 el porcentaje bajó a 64,6 \%. Si bien este descenso puede deberse a una mayor diversidad religiosa, ha beneficiado principalmente al llamado grupo evangélico, que incluye a los protestantes tradicionales, cuyo peso no ha variado mucho entre la población y, sobre todo, a los seguidores de las iglesias pentecostales y neopentecostales. En 2010, los evangélicos alcanzaron el 22,2 $\%$ de la población (IBGE, 2010). 
Gráfico N 3: Evolución de la adscripción religiosa en Brasil (1995-

2018)

\section{Evolución adscripción religiosa en Brasil}

1995 - 2018

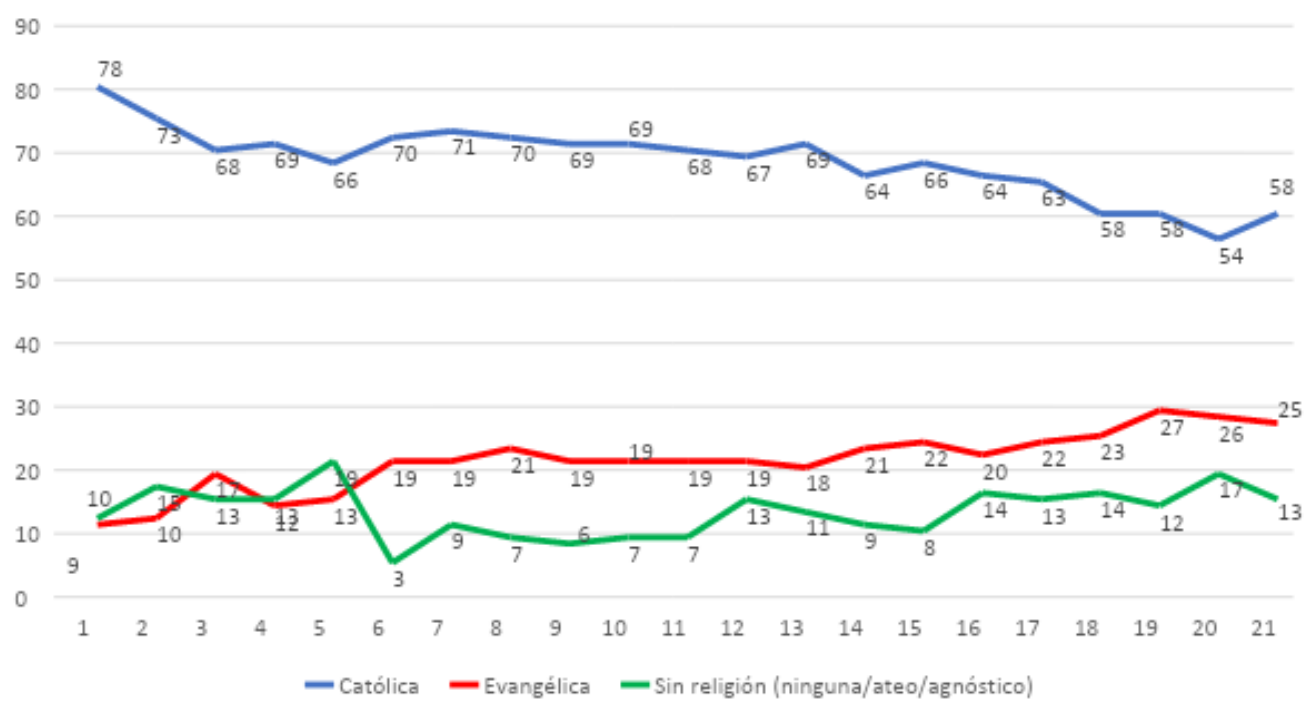

Fuente: elaboración propia en base a Latinobarómetro 2018

Hay una clara correlación entre la adhesión al evangelismo y el voto a Bolsonaro (Oualalou, 2019), ya que en los estados en donde el evangelismo ha ganado presencia (como Río de Janeiro) han ofrecido al excapitán del ejército una victoria avasallante. Varios factores han sido identificados por la autora para explicar la victoria de Bolsonaro, entre ellos el resultado de la alianza entre los militares, los neoliberales y los evangélicos. Además, Bolsonaro logró captar el rechazo escondido de un sector de la población hacia la "era de los derechos" en favor de las minorías (las mujeres, los indios, los homosexuales, los afrodescendientes). Asimismo, dicho sector de la población (clases mediasbajas que trabajan en la precariedad) entendió que el actuar del Partido de los Trabajadores (PT) como gobierno había sido corrupto, que se había encargado de las minorías LGTB y de los más pobres a través de un intervencionismo del Estado, pero se había olvidado de ellos. Todo esto, sumado al apoyo que le otorgó la Iglesia Universal del Reino de Dios (IURD), la difusión de fake news, 
apoyados por las redes sociales de WhatsApp y la cadena Record (segundo canal más visto en Brasil, herramienta mediática de la Iglesia Universal), lograron una gran capilaridad entre los evangélicos. Bajo el lema "hermano vota a hermano", todas las iglesias evangélicas, desde las tradicionales hasta las neopentecostales, llamaron a votar por Bolsonaro en las elecciones de 2018.

En opinión de Oro (2003), primeramente, los evangélicos siguen y aceptan las reglas de la vida democrática y del juego político establecido; en segundo lugar, por su discurso crítico contra determinados procedimientos políticos antiéticos, por la denuncia de la situación difícil en que se encuentran largos sectores de la sociedad, contribuyen, aunque sea de forma indirecta, a la consolidación democrática en Brasil; en tercer lugar, los evangélicos constituyen una fuente de movilización política de sectores sociales desfavorecidos. Para muchas personas, participar de una iglesia como la IURD constituye su primera experiencia de conversar sobre política y valorizar el voto. Si eso ocurre para ciertos segmentos sociales, la política no pasa más rigurosamente por las instancias tradicionales de su expresión, tales como sindicatos, cooperativas y partidos políticos. Ser evangélico se tornó en una nueva variable en este juego de relaciones entre campo político y campo religioso, por lo cual "una buena postura epistemológica sería no subestimar la inserción evangélica en la política (brasileña y latinoamericana), reduciéndola a una simple manifestación de una cultura religiosa corporativa, sino supervalorizarla, viéndola como potencializadora de la democratización de la cultura política brasileña" (Oro, 2003, p. 65).

La inserción y la presencia evangélica en el campo político adoptaron características distintas de las del catolicismo, ya que la Iglesia católica rechaza la participación de miembros del clero en cargos políticos a los que se accede por vía del sufragio (Oro y Tadvald, 2019). Eso no significa que la Iglesia católica se distancie de la vida política, pero generalmente actúa por medio del lobby y la presión sobre las autoridades y los poderes políticos, para de ese modo regular y legislar sobre políticas públicas afines a los principios católicos. Sin embargo, los evangélicos eligen sus propios representantes en el Poder 
Legislativo para que estos defiendan los principios y valores de su iglesia, fenómeno que ocurre desde la década de 1980, cuando aquellos abandonan su aversión hacia la política. El principal motivo para movilizar el electorado, compuesto por fieles y simpatizantes de esas iglesias, es diseminar la moral cristiana en el espacio político y transformar Brasil en una nación guiada por Dios. "En paralelo a ese discurso moralizante, existen también varias razones no explícitas que llevan a las iglesias a ingresar en la política: obtener favores y concesiones -como frecuencias en radio y televisión- y recibir apoyos concretos para proyectos asistencialistas" (Oro y Tadvald, 2019, p. 64).

Mariano (2005) señala que, si bien la composición social de los evangélicos ya no se restringe a los estratos más pobres, los pentecostales siguen creciendo mayoritariamente en la base de la pirámide social. Las iglesias pentecostales y neopentecostales no crecen por ser repositorios pasivos de individuos anómicos, al contrario de lo que podían explicar antiguas teorías sociológicas. "Crecen aceleradamente porque trabajan mucho y saben explotar, en su beneficio institucional, los contextos socioeconómico, político, cultural y religioso en donde están insertas" (Mariano, 2005 s.p) ). El éxito proselitista junto a las masas pobres resulta de su denodado esfuerzo y empeño por atraerlas, persuadirlas y reclutarlas mediante una oferta sistemática de servicios mágico-religiosos con fuerte apego popular, y de la realización de cultos con una alta carga emocional. Todo ello sumado a la propaganda personal y electrónica que se difunde en horarios nocturnos, de testimonios de fieles bien narrados de conversión y obtención de milagros y bendiciones.

Los pentecostales se autoexcluyeron de la vida pública hasta los años ochenta. En el período más represor de la dictadura de Brasil, los gobiernos militares, privados del apoyo católico y, por eso, interesados en lograr nuevas bases sociales para legitimar su autoridad, lograron establecer alianzas con diversos líderes evangélicos (protestantes y pentecostales), debido a que muchos de ellos eran dotados de un genuino y encarnizado anticomunismo, inclinados, en mucho casos, al clientelismo y, en condiciones de representantes de una minoría religiosa discriminada, ávidos por recursos, reconocimiento 
social y político. De todas maneras, dichos religiosos permanecieron mayoritariamente alejados del juego político-partidario durante la dictadura, alienados frente al activismo político de grupos católicos considerados progresistas, como las CEB. Hacia mediados de los años ochenta, se dio una inversión de las creencias, respecto de las cuales varias iglesias pentecostales cambiaron su comportamiento político, siendo el lema "creyente no se mete en política" sustituido por el lema "hermano vota a hermano". El cambio sustancial del comportamiento político de los pentecostales se dio en el momento de la redemocratización del país (1987-1988), cuando fue electa la "bancada evangélica", compuesta por 32 diputados federales (18 de ellos pentecostales). Con ello, la representación pentecostal que en la legislatura anterior tenía apenas dos parlamentarios, creció $900 \%$ (Mariano, 2005).

En la actualidad, en diversos debates públicos y en la propia actividad parlamentaria de Brasil, cada vez más los evangélicos se asumen como conservadores y de derecha y alegan que sus valores y su modo de vida religiosos están bajo el feroz ataque por parte de sus enemigos, identificados como la izquierda, los petistas, los comunistas, los bolivarianistas, los grupos feministas y LGBTs, los defensores de la laicidad del Estado y de los derechos humanos y sexuales.

Campos Machado (2018) es reconocida en el ámbito académico brasileño por sus aportes al estudio de la diseminación del discurso cristiano en torno a la "ideología de género" en la esfera política y en la sociedad civil por parte de actores católicos y evangélicos, los cuales rechazan la adopción de la categoría de género en las políticas públicas. La autora muestra las articulaciones de los católicos y evangélicos en el Congreso Nacional para revertir algunas políticas que incorporaban la perspectiva de género, y a su vez, la actuación de los dirigentes católicos y evangélicos en la sociedad civil en el intento de evitar la inclusión de la perspectiva de género y la orientación sexual en los planes de educación estaduales y municipales. 
Estamos frente a una disputa que envuelve segmentos organizados en movimientos sociales, ONGs e instituciones confesionales con visiones del mundo e intereses bien distintos: los cristianos con lectura a-histórica de la biblia, con una concepción heteronormativa y patriarcal de la sociedad, y los sectores sociales que valorizan la autonomía de los sujetos sobre sus cuerpos y sexualidad. (Campos Machado, 2018, p. 13).

Se trata de una disputa moral y de construcción social de una nueva forma de moralidad por parte de los movimientos sociales.

Silveira Campos (2005), por su parte, elabora dos tipos ideales: los "políticos evangélicos" y los "políticos de Cristo". Mientras que los primeros construyen sus carreras con un discreto apoyo de las iglesias, los últimos son "producidos" por megaiglesias pentecostales, que los seleccionan, promocionan y posibilitan su elección. Asumen una militancia como "vocación misionera", como un "llamado divino" y, en contrapartida, son fieles a las iglesias y sus jerarquías, defendiendo en las cámaras legislativas los intereses corporativos y morales de la institución.

Los aportes de Lopes Cabral (2006) indican que la inserción de los evangélicos en la política, se debe a que las iglesias evangélicas, en especial las iglesias pentecostales y neopentecostales, "encuentran un contexto favorable para una actuación como mediadoras de la relación sociedad/estado” (p. 92). En el contexto actual, la mediación que antiguamente realizaban los partidos políticos entre la sociedad y el Estado ha ido perdiendo relevancia, y se extiende la democracia a espacios más amplios de la sociedad civil. En Brasil, las iglesias evangélicas llegan a áreas marginales de la sociedad y consiguen movilizar las comunidades de un modo de condicionar su opción a la hora del voto. Son espacios en donde el Estado no llega, constituyéndose estas iglesias como un actor relevante a la hora de mediar entre las nuevas demandas de la sociedad y el Estado.

En cuanto a la especificidad del caso brasileño, utilizando la tipología de Pérez Guadalupe (2019) encontramos la presencia simultánea de los tres modelos, a saber: i) partidos evangélicos, ii) frente evangélico y iii) facción 
evangélica. Por otra parte, se destaca en este caso la producción de "políticos de Cristo" (las iglesias adoptan candidaturas oficiales y las promocionan a sus fieles) y la actuación de las iglesias como partidos paralelos. Todo ello se da en un contexto de alta fragmentación partidista (los partidos políticos son débiles y tienen sus fronteras diluidas) y de la magnitud de los distritos electorales.

Las iglesias que tienen mayor participación en la política son la IURD (con su Partido Republicano Brasilero), y las Asambleas de Dios (identificadas mayormente con el Partido Social Cristiano), las cuales han catapultado buena parte de los diputados federales evangélicos electos en las últimas décadas (Lacerda y Brasiliense, 2019).

\section{La politización evangélica en la Argentina contemporánea}

En Argentina, la relación entre la Iglesia católica y el Estado, por su mayor visibilidad pública y por su posición monopólica, es la que se presenta como la más evidente en el juego de relaciones y negociaciones existentes entre el campo religioso y el campo político. Asimismo, una vasta bibliografía académica da cuenta de esta relación en los estudios sobre religión y política.

\section{Gráfico Nº 4: Evolución de la adscripción religiosa en Argentina (1995- 2018)}

Evolución de la adscripción religiosa en Argentina 1995 - 2018

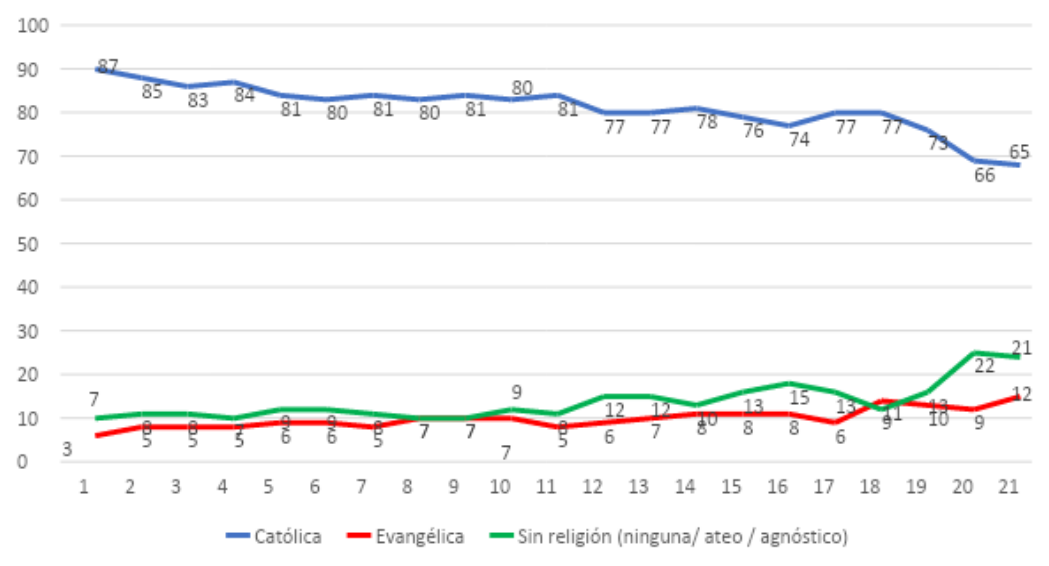

Fuente: elaboración propia en base a Latinobarómetro 2018 
Antes del regreso a la democracia en Argentina (1983), el mundo evangélico estaba dominado por un paradigma misionero, el énfasis en la preservación de una identidad denominacional y por el apoliticismo y aislamiento social (Carbonelli y Jones 2015; Carbonelli 2011). En la década de 1960 se produjo una fractura, resultando que una parte de la comunidad evangélica (metodistas, valdenses, luteranos) se acerca a la teología de la liberación, y otros grupos (iglesias como los Hermanos Libres y el Ejército de la Salvación) se incorporan a la corriente fundamentalista del contexto estadounidense de posguerra, que se vio fortalecida por la nueva derecha cristiana. Los golpes de Estado de la década de 1970 en el Cono Sur acentuaron esa división. El primer bloque de iglesias apoyó al sector progresista católico y al Movimiento Ecuménico por los Derechos Humanos, mientras que el otro sector dio su apoyo a la dictadura cívico-militar en Argentina.

El retorno y la consolidación del régimen democrático en Argentina favoreció una creciente participación de los evangélicos en el espacio público durante las décadas de 1980 y 1990. Las campañas proselitistas de líderes pentecostales propiciaron la constitución de un movimiento social evangélico por la emergencia de una identidad común. A su vez, los dirigentes pentecostales modificaron su relación con las estructuras mundanas, aceptando participar de ellas para transformar la sociedad desde una perspectiva evangelizadora. (Carbonelli y Jones, 2015, p. 145).

Wynarczyk (2009) subraya que desde el regreso a la democracia en Argentina los evangélicos desarrollaron una fuerte identidad como la principal minoría religiosa a partir de la protesta por la igualdad religiosa frente al estatus privilegiado que posee la Iglesia católica en dicho país. Al respecto, llevaron adelante un ciclo de movilizaciones desde 1990 hasta 2001. Dicho movimiento "de pocos" no dejó de sentirse estigmatizado, pero tuvo su impacto en el periodismo y en el poder judicial y legislativo. Los evangélicos sabían que en 1994 habría una reforma constitucional, y contaban con cierta apertura en la 
Secretaría de Culto de la nación, conducida por católicos liberales (en contraste con la derecha nacionalista que asociaba la Iglesia con el "ser nacional").

En esas circunstancias desarrollaron un creciente movimiento de protesta que llegó al apogeo en multitudinarias concentraciones en 1999 y 2001. Los evangélicos no obtuvieron ningún resultado legal, a raíz de una sumacero entre partes involucradas, pero se constituyeron en un sujeto público en la vida cívica de la nación. (Wynarczyk y Oro, 2012, p. 30).

En 2001 Argentina atravesó una situación de crisis política y económica, y la movilización evangélica disminuyó, realizándose una única concentración en 2003, con menor éxito, y luego los evangélicos abandonaron la acción colectiva. En este proceso de movilización se involucraron fieles de todo el espectro evangélico, pero el centro estuvo en los conservadores bíblicos, aunque los pentecostales jugaron un rol importante también.

Frigerio (2019) hace énfasis en que el crecimiento de los evangélicos se debe más a los contactos que el individuo tenga con miembros del grupo que a la publicidad realizada en los medios de comunicación (programas televisivos y radiofónicos). Los creyentes pentecostales se conectan a una nueva red de relaciones personales al ingresar a una iglesia, lo que mejora su acceso a la circulación de bienes y servicios para la subsistencia en condiciones precarias: "ayuda laboral, cuidado de niños o ancianos, alojamiento a migrantes, acceso a viviendas e información sobre trabajos o servicios" (Frigerio, 2019, p. 52; Frigerio, A. y Wynarczyk, 2013).

Algranti (2010) estudia desde una óptica más micro, aquellos aspectos más cercanos a las prácticas cotidianas que a los grandes actos públicos. El autor da cuenta de otras formas de hacer política a partir de cómo una iglesia neopentecostal ("Rey de reyes") supo conquistar aquellos espacios que tanto las instancias estatales como la Iglesia católica dejaron libres, a partir de una estructura que habilita múltiples y cambiantes formas de intervención en la sociedad dentro de las cuales la política partidaria, el Estado y la sociedad civil pueden pasar al centro de la escena. "Rey de reyes" tiene un modelo de iglesia 
"hacia afuera", donde se exploran las orientaciones religiosas al mundo a partir de tres claves: las formas de violencia y el sufrimiento social, la construcción colectiva de un diagnóstico sobre la situación del país y el posicionamiento de los "líderes cristianos" como agentes de transformación social. El campo de acción del neopentecostalismo se enfoca en el sujeto, los valores, la familia, el barrio, el entorno laboral, las necesidades sociales y otros ámbitos desprestigiados por la política. La religión, “el evangelio", es una propuesta de cambio social que se superpone a todas las esferas de la vida. Por este motivo, dicha iglesia se destaca por actuar en espacios concretos en el ámbito de la familia, la educación y la asistencia, pero no posee una participación relevante en la política partidaria (Algranti, 2010; Mosqueira y Algranti, 2019).

Desde la década de 1990 hasta la actualidad, el nepentecostalismo avanza hacia "una institucionalización creciente de su presencia en la sociedad" (Algranti y Mosqueira, 2018, p. 306). Ello se debe a varios factores: i) se establece en el espacio público; ii) aumenta la complejidad de su organización; iii) logra alcanzar geográficamente a zonas de mayores ingresos; iv) tiene formación de capacidades de líderes con influencia política y en los medios de comunicación; v) explota las industrias culturales apoyadas en nuevas tecnologías; vi) crea fundaciones para la asistencia a sectores desfavorecidos; vii) construye un sujeto juvenil cristiano a partir de circuitos de eventos. Es de destacar la creación por parte de los evangélicos de modelos de intervención sobre dominios abandonados de la sociedad, en zonas menos visibles como cárceles, institutos de menores y el trabajo con consumos problemáticos, desarrollando así una metodología específica en el tratamiento de adicciones desde una perspectiva espiritual. Hay numerosos estudios que señalan que la religiosidad es un factor protector ante el consumo de drogas en diferentes contextos culturales (Algranti y Mosqueira, 2018).

Algranti y Mosqueira (2018) demuestran que el Estado y los grupos religiosos confluyen en el Programa Inclusión de Tratamiento de Adicciones, demostrando que hay una articulación entre las redes públicas y las evangélicas, entre el mundo religioso y el de las políticas públicas. 
Los evangélicos se convierten en actores a través de los cuales el estado ejecuta políticas de salud en consumos problemáticos, capitalizando su alcance territorial, su metodología y experiencia. Y, a su vez, las estructuras gubernamentales introducen - no sin tensiones y resistenciasel punto de vista espiritual en el desarrollo de políticas públicas, es decir, en los programas y planes de acción que le permiten al estado definir prioridades y actuar sobre ellas. (Algranti y Mosqueira, 2018, p. 318).

Mosqueira (2019) estudia además cómo el rock evangélico viabilizó el desarrollo del evangelismo pentecostal en los sectores juveniles, dejando de manifiesto la transnacionalización de una industria cultural dirigida a los jóvenes evangélicos.

Cynthia Hotton, evangélica, fue electa diputada en 2007 integrando una alianza de partidos no peronistas. En 2008 formó la agrupación política "Valores para mi país", que sigue la línea conservadora de la megaiglesia pentecostal: rechazo a la legalización del aborto, rechazo al matrimonio entre personas del mismo sexo y define a la familia como una institución patriarcal y heterosexual. Una de sus propuestas fue extender las prerrogativas de la Iglesia católica a las demás religiones, la cual no prosperó (Carbonelli, 2016).

Hotton obtuvo una distinción por parte de la organización internacional Enfoque a la familia, como 'defensora de la vida en Latinoamérica', y esta mención le valió la organización de un ciclo de conferencias propio, donde actualmente asesora a diputados cristianos latinoamericanos en debates como aborto, unión de parejas de mismo sexo, fertilización asistida y eutanasia. En definitiva, Hotton prolongó su trayectoria política a partir de su conversión en embajadora 'global' de los valores cristianos en la arena partidaria. (Carbonelli, 2016, p. 208).

En las últimas elecciones Primarias Abiertas Simultáneas y Obligatorias (PASO) en la Argentina (2019), el frente NOS se colocó como la quinta fuerza política, presentando como candidato presidencial al exmilitar Juan José Gómez Centurión y a la exdiputada evangélica Cynthia Hotton. Es una propuesta política nueva que se opone al aborto, capitalizando lo que se conoce como el 
"voto celeste" (provida y profamilia). Asimismo, las iglesias evangélicas demostraron en la Argentina un poder de convocatoria relevante en las manifestaciones durante el debate por la legalización del aborto. Se trata, en definitiva, de un conglomerado que abarca según la Segunda Encuesta del CEIL-CONICET (Mallimaci, Giménez Béliveau, Esquivel e Irrazábal, 2019) al 15,3 \% de la población argentina (un $13 \%$ son pentecostales y un 2,3\% corresponde a otros evangélicos), fenómeno religioso que experimentó un fuerte crecimiento en los últimos cincuenta años (el censo de 1960 arrojó que eran el 2,3 \%) (Rubin, 23 de junio de 2019).

Otras figuras evangélicas relevantes en la política son Miriam Ruth Boyadjian (senadora Nacional del Movimiento Popular Fueguino por la provincia de Tierra del Fuego entre 2015 y 2019) y David Schlereth (diputado de la nación para el período 2017-2021 del Partido Pro, pastor evangélico). También hay numerosos evangélicos elegidos como concejales en las legislaturas municipales y evangélicos en las oficinas de culto de los municipios y gobiernos provinciales (Wynarczyk, 2019).

Dos elementos claves para comprender el modelo de la participación política de los evangélicos en Argentina son el anclaje territorial y la afinidad con el peronismo. Tomando en cuenta la tipología de Pérez Guadalupe (2019), en Argentina hoy por hoy encontramos el modelo de la "facción evangélica", aunque en el pasado existieron partidos políticos confesionales, pero fracasaron. La particularidad es que los grupos evangélicos han abandonado la vía partidaria propia, pero sí han consolidado una movilización en las calles y han penetrado en las políticas públicas. Otra singularidad del caso argentino es que la mayoría de los votantes evangélicos no tiene preferencia por partidos de derecha, sino que se inclina por el peronismo.

Una coincidencia con el caso brasileño y el uruguayo es la obra social que realizan las iglesias evangélicas sobre dominios de la sociedad abandonados, tales como las personas que poseen adicciones, personas privadas de libertad, víctimas de violencia de género, todo lo que ha llevado a 
Wynarczyk (2019) a decir que los evangélicos trabajan en los "sótanos de la nación” (p. 219).

\section{Los evangélicos avanzan en el escenario político uruguayo}

Uruguay, la estrella más secularizada del firmamento religioso latinoamericano, comienza a percibir lentamente el incremento de figuras políticas públicamente reconocidas como evangélicas en la arena política.

Gráfico No5: Evolución de la adscripción religiosa en Uruguay (1995-

2018)

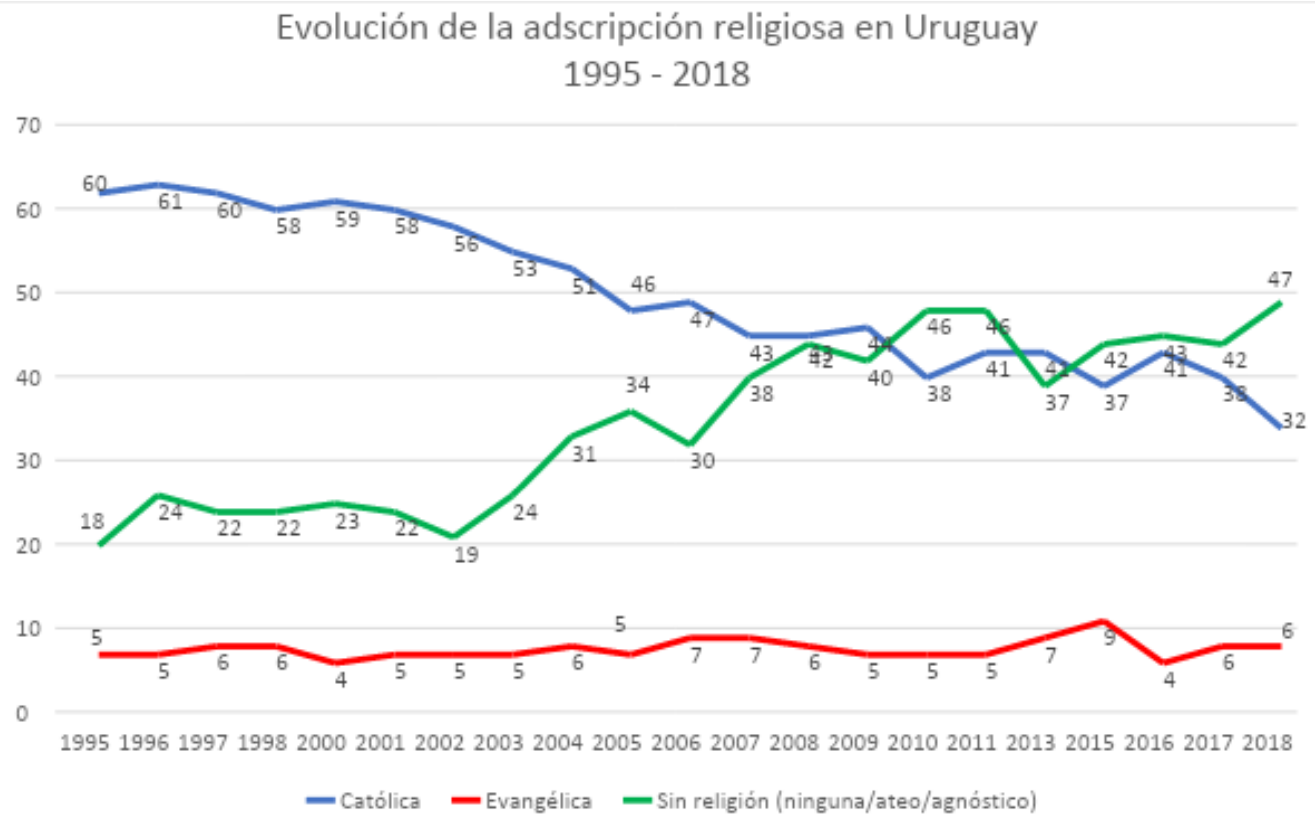

Fuente: elaboración propia en base a Latinobarómetro 2018

El primer evangélico que irrumpe en la arena política uruguaya es el diputado herrerista Dr. Gerardo Amarilla (Partido Nacional), abogado, miembro de una iglesia evangélica de corte pentecostal (Asambleas de Dios). Amarilla fue diputado por el departamento de Rivera en el período 2010-2015 y fue reelecto para los períodos 2015-2020 y 2020-2025, habiendo ocupado el cargo de edil de la Intendencia de Rivera en el período 2000-2010. Él fue quien 
formuló la controvertida frase al asumir su banca: "La ley de dios está por encima de la república". Fue designado en agosto de 2020 por el presidente Luis Lacalle Pou como subsecretario del Ministerio de Ambiente, cartera estatal recientemente creada, cargo que ocupa hasta la actualidad.

Otra figura relevante cuando hablamos de política y religión es el diputado Álvaro Dastugue, electo por el sector Alianza Nacional, Partido Nacional. Dastugue es el primer pastor evangélico en la historia de la política uruguaya en ocupar una banca; su filiación institucional es la iglesia neopentecostal Misión Vida para las Naciones, cuya figura más relevante es el apóstol Jorge Márquez.

La tercera figura política del ámbito evangélico es Benjamín Irazábal, diputado herrerista por Durazno, también perteneciente al Partido Nacional. Los tres mencionados diputados titulares repitieron su banca para el período 20202025, ya que también ejercieron como diputados en el período 2015-2020, sumándose en el anterior período el diputado suplente Luis Pintado por el Partido Colorado (el cual había asumido en 2018 en carácter de titular la banca tras ser formalizada la renuncia del titular) y dos diputadas nacionalistas suplentes: Betiana Britos (Partido Nacional, sector Alianza Nacional) y Grisel Pereyra (Partido Nacional, sector Esperanza Nacional). Todo ello condujo a que se comenzara a hablar en el quinquenio pasado de la existencia de una "bancada evangélica". Sus integrantes lo han negado, ya que alegan no poseer agenda propia ni una coordinación específica. Actualmente, en los gobiernos departamentales encontramos más de una decena de ediles evangélicos (titulares y suplentes) y dos cargos de confianza en las intendencias de Rivera y Cerro Largo.

Al comienzo de la pasada legislatura (2015-2020) fueron 16 personas (entre diputados, ediles y cargos de confianza) las que recibieron la bendición en una ceremonia denominada "consagración a cristianos en el gobierno". En ella se comprometieron a respetar la Constitución y las leyes "siempre y cuando no contradigan la palabra de dios". Aseguraron que acatarían "los dictados" de sus consciencias "informados por la palabra de dios, por encima de toda lealtad 
personal o partidaria", y dijeron que la "base" y el "fundamento" para su actividad sería el evangelio. Son siete áreas de la sociedad uruguaya en donde los evangélicos que se encuentran trabajando en política y buscan tener influencia: gobierno, iglesia, familia, economía, cultura, artes y comunicación (El País, 13 de septiembre de 2015, s. p.).

Sin lugar a dudas, la figura política principal de los votantes evangélicos ha sido una mujer perteneciente al Partido Nacional, católica convertida al judaísmo: la exsenadora nacionalista Verónica Alonso (período 2015-2020). Alonso fue una de las figuras políticas más visibles en contra de la ley "trans" cuando se discutió en el Parlamento. Encarna los mismos valores que promueven las iglesias neopentecostales, principalmente el valor de la familia tradicional y la defensa al valor de la vida. Ella ha despertado la sombra del oficialismo por el supuesto aporte de la Iglesia Misión Vida en la financiación de su campaña pasada (2014), ya que quedó una factura impaga en una imprenta a nombre de una persona relacionada con la iglesia (Gabriel Cunha), lo que llevó a un litigio judicial. El aporte de los religiosos en la campaña de Alonso fue analizado por la Comisión investigadora sobre financiamiento de los partidos políticos, y la denuncia de internos del Hogar Beraca repartiendo sus listas fue investigada por la Comisión de Derechos Humanos del Parlamento por explotación laboral de los jóvenes internados en esa comunidad. En el actual gobierno, Cunha fue designado director de la División de Coordinación de Programas de Personas en Situación de Calle del Ministerio de Desarrollo Social. A nivel religioso, se define como evangélico practicante sin iglesia definida. Pertenece en este momento al sector "Unidos" dentro del Partido Nacional.

En 2012 se aprobó en Uruguay la interrupción voluntaria del embarazo y desde 2013 rige la Ley de Matrimonio Igualitario; también en 2013 se aprobó la Ley de Regulación y Control del Cannabis (Ley No 19.172), y en 2018 se aprobó la Ley Integral para Personas Trans. A todas estas, los evangélicos (mayormente los de corte pentecostal) se oponen en forma sistemática. Actualmente, realizan una fuerte ofensiva contra la "agenda de derechos", 
incluso en 2019 recolectaron firmas para realizar un prerreferendum para derogar la Ley Integral para personas trans, proceso que finalmente no tuvo éxito. El Sr. Carlos Iafigliola, político perteneciente al Partido Nacional, precandidato a presidente por su partido en las elecciones internas de junio de 2019, fue el promotor del prerreferendum. Iafigliola se identifica como católico carismático y tuvo el apoyo durante este proceso de los evangélicos neopentecostales, principalmente del diputado Álvaro Dastugue. Este político justificó su iniciativa expresando que la ley "trans" es "inconstitucional, peligrosa e injusta" (Radio Universal, 14 de noviembre de 2018). Iafigliola desarrolló su pensamiento expresando que seguía el proyecto desde que fue presentado por la exsenadora trans Michele Suárez (del Partido Frente Amplio). Él considera que es peligroso que se le dé marco a la posibilidad de que menores de edad puedan llevar adelante procesos de hormonización y cambio de sexo. Afirma que, si bien cualquier persona mayor puede hacerse el cambio de sexo, es injusto que el Estado garantice gratuitamente el proceso, ya que no logra cubrir necesidades básicas en temas de salud, medicamentos de alto costo o cirugías.

Por otra parte, también vale consignar que los evangélicos (mayormente los pentecostales y neopentecostales) se muestran contrarios a la educación sexual en las escuelas, tal como se ha manifestado en varias oportunidades el líder de la Iglesia Misión Vida para las Naciones, el apóstol Márquez, al señalar que "los manuales de sexualidad del gobierno incitan a la pedofilia y que el 'lobby gay' busca legalizar el sexo con menores" (García, 9 de noviembre de 2018, p. 2).

En lo que respecta al aborto, los evangélicos reprueban su práctica y han manifestado en numerosas entrevistas de prensa que pretenden derogar la ley. Una prueba de ello es un proyecto presentado en 2016 por Dastugue e Irazábal -el cual no prosperó- de celebrar el 25 de marzo el "Día del niño por nacer”. El referéndum para derogar la ley de despenalización del aborto en 2013 no llegó a las firmas necesarias, pero esto no asegura la persistencia de la ley, ya que el mismo Iafigliola promete continuar trabajando para anularla. 
Por su parte el diputado Dastugue ha manifestado que la discusión en el Parlamento de la Ley de Regulación de la Marihuana ha sido lo que lo ha empujado a militar en política. Aduce que debido a que en los hogares Beraca de la Iglesia Misión Vida se realiza un trabajo social de atención a los usuarios que presentan consumo problemático de drogas, por tal motivo se muestran contrarios a esta ley.

Los evangélicos también tejen alianzas con movimientos sociales y ONG provida y profamilia, como el existente en Uruguay denominado "A mis hijos no los tocan", surgido como rechazo a la propuesta didáctica para el abordaje de la educación sexual en educación inicial y primaria, presentada por el Consejo de Educación Inicial y Primaria.

Durante algunos meses de 2019, por primera vez en la historia política del Uruguay coincidieron en el Parlamento cuatro diputados evangélicos. En ese quinquenio legislativo fueron presentadas 11 iniciativas por legisladores evangelistas, siguiendo las mismas convicciones religiosas: dos proyectos en contra de la despenalización del aborto, cuatro proyectos de ley asociados a la prohibición y tratamiento de drogas, cuatro que promovían la familia “tradicional” y uno que establecía el 31 de octubre como el "Día nacional de las iglesias evangélicas".

Finalmente, el asunto del matrimonio igualitario también es un flanco al que apuntan los evangélicos, ya que el modelo familiar que defienden es el de la familia nuclear, compuesta por un hombre y una mujer. Es por tanto que se oponen también a dicha ley ya aprobada en nuestro país. ${ }^{3}$

La presencia pública del neopentecostalismo en Uruguay se comenzó a advertir según Guigou (2006) al menos desde la década de 1980. Dicho autor se refiere a la "neopentecostalización de la lengua política", pero en ese entonces afirma que en Uruguay "[n]o hay pues bancadas evangélicas, ni tampoco diferentes nominaciones del universo pentecostal disputando posiciones en la arena política" (Guigou, 2006, p. 51). Dicho diagnóstico ya no coincide con la

${ }^{3}$ Interesantes contribuciones para entender el caso uruguayo se encuentran en la tesis doctoral de Cunha Bellato (2020) y la tesis de maestría de Milsev (2020).

Arosena, F. y Sotelo, M. (2021). Desde los márgenes de la sociedad al parlamento. Evangélicos y política en Brasil, Argentina y Uruguay. Revista Cultura y Religión, 15(2), 1-38. 
realidad y muestra cómo se han desencadenado rápidamente cambios en este escenario religioso y político que nos movilizan a pensar el fenómeno desde una nueva mirada sociológica. Actores más recientes en esta superposición entre religión y política son los ejemplos mencionados de los diputados evangélicos y su accionar concreto en búsqueda de una moral cristiana que se funda en el modelo de familia tradicional, patriarcal, heterosexual y sin drogas.

El hecho más relevante de 2019 entre religión y política fue la fuerte actividad de los neopentencostales militando en contra de la Ley Integral para Personas Trans, que llevaron adelante Iafigliola y Dastugue. Aunque, como dijimos, la votación no fue suficiente para avanzar en la derogación de la ley, este movimiento permitió dos cosas: "por un lado, motivó el involucramiento bajo una misma causa de las bases conservadoras religiosas de estos sectores, $\mathrm{y}$, por otra parte, brindó la posibilidad de entrenar a las personas en el quehacer político y tener más experiencia para las elecciones" (Iglesias, 14 de septiembre de 2019 , s. p.). Es importante destacar que en esta votación en los departamentos fronterizos con Brasil fue donde los evangélicos obtuvieron mayor cantidad de adhesiones, lo que muestra una cierta internacionalización del fenómeno y la influencia del país vecino.

En Uruguay, los actores evangélicos presentes en la política no son meros acompañantes de los representantes políticos católicos, ya que el peso de la Iglesia católica no es tan fuerte en la vida política de nuestro país, en contraste con el caso argentino. Es cierto que tejen alianzas con los católicos, pero en la defensa de la agenda profamilia y provida se presentan como protagonistas de estas banderas políticas. Tienen más brillo en el escenario político, pues la Iglesia católica les da pase libre.

Actualmente encontramos evangélicos en todos los partidos políticos uruguayos: en el Frente Amplio participan políticos del ala histórica evangélica (valdenses, luteranos, hermanos libres), mientras que en el Partido Nacional son evangélicos pentecostales (y neopentecostales) mayormente. En el departamento de Rivera, en donde históricamente el Partido Colorado ha gobernado, encontramos evangélicos, mayormente pentecostales, participando 
en política, como es el caso del pastor Óscar Farías de la Iglesia Cristiana de Rivera, que se desempeña en el cargo de director del Departamento de Gestión Territorial de la Intendencia de Rivera. Dicho pastor fue convocado por el Partido Colorado por ser una figura carismática en su zona, debido a la tarea pastoral que realiza con jóvenes con consumo problemático de drogas y mujeres víctimas de violencia.

Estamos ante un escenario de unos 30 representantes evangélicos que militan en política en Uruguay y ocupan cargos de confianza en gobiernos departamentales, ediles en Juntas departamentales y diputados en el Parlamento. La Iglesia Misión Vida para las Naciones, liderada por el apóstol Jorge Márquez, es la que ha logrado mayor presencia a nivel de cargos ocupados en la política y la que ha desarrollado un aparato dedicado a la política. Luego encontramos muchas iglesias pentecostales independientes que han logrado el destaque de figuras evangélicas y pastores, como de la que proviene el diputado Amarilla, como también el pastor Gustavo Silveyra. Este, además de tener virtudes musicales que a través del rock despliega en los cultos, fue designado en el actual gobierno como director de la Dirección Nacional de Apoyo al Liberado (Dinali), Ministerio del Interior, en razón de su una vasta trayectoria pastoral previa en las cárceles. ${ }^{4}$

Tomando el modelo de Pérez Guadalupe, podemos decir que en Uruguay encontramos el modelo de la facción evangélica, con inserción de evangélicos en partidos ya existentes. No hay ni hubo partidos confesionales. El laicismo hondamente arraigado en nuestro país y la puja que se dio entre Iglesia y Estado, donde la Iglesia católica quedó relegada al ámbito de lo privado, hace que los evangélicos tengan libertad para poder desenvolverse en la política y destacarse en la misma. No obstante, las fuertes identidades partidarias que despiertan los partidos uruguayos (dos de ellos entre los más longevos del mundo: el Colorado y el Nacional; y la izquierda unida en el Frente Amplio ya

\footnotetext{
${ }^{4}$ Información recabada de las entrevistas y el trabajo de campo de Victoria Sotelo para su tesis doctoral.
} 
desde 1971), también hace muy difícil la aparición de las otras dos categorías de Pérez Guadalupe (2019): el Partido Evangélico y el Frente Evangélico.

\section{Conclusiones}

El crecimiento de las confesiones evangélicas ha impactado en la arena política de los tres países estudiados (Brasil, Argentina y Uruguay) en este artículo de diferentes maneras, si bien encontramos elementos comunes. En los tres casos existe un patrón común en la movilización de grupos evangélicos mayormente pentecostales- para debilitar la nueva agenda de derechos hacia los movimientos LGBT, el aborto legal, el matrimonio entre personas del mismo sexo y la educación sexual en las escuelas, que se articula a nivel internacional. No obstante, esto no debe generalizarse a todos los evangélicos, puesto que este campo religioso es heterogéneo y fundamentalmente los integrantes de las confesiones protestantes más antiguas e históricas en los tres países analizados tienen posiciones diversas.

En los tres países de nuestro estudio son los pentecostales quienes ostentan en la actualidad la mayor cantidad de cargos de representación nacional en el Parlamento y en otros ámbitos de participación política a nivel descentralizado, así como cargos de confianza en el Estado.

La obra social que despliegan las iglesias evangélicas en los territorios más marginados (patrón común que se encuentra en los tres países), su anclaje territorial, el trabajo misional y su activismo social, son el cimiento sobre el que se monta toda la estructura de participación política en el Parlamento. Los nuevos evangélicos, que en su mayoría son pentecostales, se permiten disfrutar del mundo a través de una "teología de la prosperidad" que legitima la vida en abundancia, sacralizan el mundo y combaten los males terrenales a través de la fe, lo que se denomina la "guerra espiritual". Ahora se han propuesto actuar en el ámbito político, estrategia que Pérez Guadalupe denomina "teología del dominio" (2019, p. 14). 
De sus templos, que se multiplican en los márgenes de las ciudades, surgen liderazgos políticos: algunos son "evangélicos políticos” (personas de fe cristiana que han llegado a la política) y otros son "políticos evangélicos" (candidaturas oficiales propuestas por las iglesias), como se ha visto muy marcadamente en el caso brasileño y en menor medida en el uruguayo.

Brasil es el caso más avanzado en la cristalización de una agenda en el Parlamento con una poderosa bancada legislativa. Las iglesias evangélicas pasaron a adoptar un modelo de representación corporativa y, en consecuencia, se involucraron en la contienda electoral con "candidatos oficiales" y postularon a cargos en los poderes legislativos municipales, estatales y federales. El caso más conocido es el de la Iglesia Universal, que durante la década de 1990 eligió decenas de obispos y pastores para la Cámara de Diputados, asambleas estatales y cámaras municipales.

Uruguay también ha visto un aumento considerable de representantes evangélicos en el parlamento en la última década, aunque no se trata de una "bancada evangélica" como la existente en Brasil.

En el caso de Argentina, si bien se destacó una diputada evangélica, los evangélicos han actuado mucho más a nivel social y territorial, buscando influir en las políticas públicas sobre drogas, por ejemplo, pero con poco interés hasta ahora en la disputa directa por la representación política. Parte de su poder de convocatoria se vio en las calles en una manifestación contra la ley del aborto. En la agenda moral provida y profamilia, los evangélicos han acompañado a la Iglesia católica, pero como meros escoltas, ensombrecidos por el papel protagónico que ocupa el catolicismo en dicho país. Lo particular del caso argentino es que los evangélicos no están identificados en sus inclinaciones electorales a partidos de derecha, sino de centro-izquierda (los pentecostales, en su gran mayoría, se identifican con el peronismo).

Los tres modelos de participación política definidos por Pérez Guadalupe están presentes simultáneamente en Brasil. Allí encontramos los partidos evangélicos, el Frente Evangélico y la facción evangélica. Se destaca aquí además la construcción de "políticos de Cristo" (candidaturas oficiales) y 
las iglesias que actúan como partidos paralelos. Todo ello se da en un contexto político de alta fragmentación partidaria (los partidos políticos son débiles y tienen límites diluidos) y en atención a la magnitud de los distritos electorales. También existe una diferencia significativa en Brasil, donde el lema "hermano vota al hermano" ha logrado una considerable adhesión entre los seguidores evangélicos.

No ocurre lo mismo en los otros dos países, donde el crecimiento demográfico de los evangélicos no se traduce plenamente en votos para los políticos evangélicos. En la actualidad, no encontramos ni en Argentina ni en Uruguay ni partidos, ni frentes, pero se ve claramente la presencia de facciones evangélicas, donde los creyentes optan por participar en política desde dentro de partidos bien establecidos, como es el caso del peronismo en Argentina, o de los tres principales partidos políticos en Uruguay, pero con una notoria preferencia por el Partido Nacional.

\section{Referencias bibliográficas}

Algranti, J. (2010). Política y religión en los márgenes. Nuevas formas de participación social de las megaiglesias evangélicas en la Argentina. Buenos Aires: Ediciones Ciccus.

Algranti, J. y Mosqueira, M. (2018). Sociogénesis de los dispositivos evangélicos de "rehabilitación" de usuarios de drogas en Argentina. Salud Colectiva, 14(2), 305-322.

Bayce, R. (2 de julio de 2017). Los evangélicos avanzan en política y religión. Revista Caras y Caretas [edición online]. Recuperado de https://www.carasycaretas.com.uy/los-evangelicos-avanzan-politicareligion/

Burity, J. (2008). Religión, política y cultura. Tempo Social, 20(2), 83-113.

Campos Machado, M. (2018). O discurso cristiao sobre a "ideología de genero". Revista Estudos Feministas, 26(2), 1-18.

Carbonelli, M. (2016). "Los evangélicos y la arena partidaria en la Argentina contemporánea”. Estudios Políticos, 37: pp 193-219.

Carbonelli, M. y Jones D. E. (2015). Igualdad religiosa y reconocimiento estatal: instituciones y líderes evangélicos en los debates sobre la

Arosena, F. y Sotelo, M. (2021). Desde los márgenes de la sociedad al parlamento. Evangélicos y política en Brasil, Argentina y Uruguay. Revista Cultura y Religión, 15(2), 1-38. 
regulación de las actividades religiosas en Argentina, 2002-2010. Revista Mexicana de Ciencias Políticas y Sociales, LX(225), 139-168.

Carbonelli, M. (2011). Ciencias Sociales, evangélicos y política. Una lectura sobre la producción científica acerca de la participación política evangélica en la vida democrática argentina (1983-2010). Revista Cultura\&Religión, 5(2), 96-116.

Cunha Bellato, C. (2020). Sob a lei de Deus: evangélico e política no Uruguay. (Tesis doctoral). Pontificia Universidade Católica do Rio de Janeiro, Río de Janeiro, Brasil.

El País (13 de septiembre de 2015). Evangélicos que tienen banca. El País, sección Qué pasa. Recuperado de https://www.elpais.com.uy/quepasa/evangelicos-banca.html [Visitado el 30 de mayo de 2021].

Escobar, D. y Núñez, P. (2020). El establecimiento y expansión de la misión evangélica The Christian and Missionary Alliance en el sur de Chile (1897-1905). Revista Cultura\&Religión, 14(2), 56-78.

Freston, P. (2012). Las dos transiciones futuras: católicos, protestantes y sociedad en América Latina. En C. Parker (ed.), Religión, política y cultura en América Latina. Nuevas miradas (pp. 77-94). Santiago: Instituto de Estudios Avanzados de la Universidad de Chile- Asociación de Cientistas Sociales de la Religión del Mercosur.

Frigerio, A. (2019). La experiencia religiosa pentecostal. Nueva Sociedad, N. 280, 47- 67.

Frigerio, A. y Wynarczyk H. (2013). "La diversidad religiosa argentina: un desafío a la ciencia normal”. Revista Cultura y Religión, 7 (1), pp. 3-9.

García, D. (9 de noviembre de 2018). Vienen Bajando. Los evangélicos y su vínculo con la política. Semanario Brecha. Recuperado de https://brecha.com.uy/vienen-bajando/ [Visitado el 30 de mayo de 2021].

Guigou, N. (2006). Religión y política en el Uruguay. Civitas. Revista de Ciências Sociais, 6(2), 43-54.

Informe Rockefeller (1970). Foro Internacional, El Colegio de México. Vol. 10, N. 3 (39) (enero-marzo, 1970), pp. 286-344. Recuperado de (https://forointernacional.colmex.mx/index.php/fi/issue/view/41)

Visitado el 21 de octubre de 2021

Iglesias, N. (14 de septiembre de 2019). Mapa político religioso de cara a las próximas elecciones. La Diaria. Recuperado de 
https://ladiaria.com.uy/politica/articulo/2019/9/mapa-politico-religiosode-cara-a-las-proximas-elecciones/.

Instituto Brasileiro de Geografía e Estadística (IBGE) (2010). Censo 2010. IBGE [sitio web]. Recuperado de https://censo2010.ibge.gov.br/ [Visitado el 31 de mayo de 2021].

Lacerda, F. y Brasiliense, J. M. (2019). Brasil: la incursión de los pentecostales en el Poder Legislativo brasileño. En J. L. Pérez Guadalupe y S. Grundberger (eds.), Evangélicos y poder en América Latina (2 $2^{\mathrm{da}}$ ed.) (pp. 223-260). Lima: Konrad Adenauer-Instituto de Estudios Social Cristiano.

Latinobarómetro (2018). Base de datos de la encuesta de 2018. [En línea]. Recuperado de latinobarometro.org

Levine, D. (2006). Religión y política en América Latina. La nueva cara pública de la religión. Revista Sociedad y Religión, 18(26-27), 7-29.

Ley $\mathrm{N}^{\circ}$ 18.987. Ley sobre interrupción voluntaria del embarazo. Promulgada el 22 de octubre de 2012. Parlamento de Uruguay. Recuperado de https://www.impo.com.uy/bases/leyes/18987-2012

Ley No 19.075. Matrimonio igualitario. Promulgada el 3 de mayo de 2013. Parlamento de Uruguay. Recuperado de https://www.impo.com.uy/bases/leyes/19075-2013

Ley No 19.172. Regulación y Control del Cannabis. Promulgada el 20 de diciembre de 2013. Parlamento de Uruguay. Recuperado de https://www.impo.com.uy/bases/leyes/19172-2013

Ley $N^{\circ}$ 19.684. Ley Integral para Personas Trans. Promulgada el 26 de octubre de 2018. Parlamento de Uruguay. Recuperado de https://www.impo.com.uy/bases/leyes/19684-2018

Lopes Cabral Maia, E. (2006). Os evangelicos e a política. Revista Electronica dos pos graduandos em Sociologia Política da UFSC, 2(4), 91-112.

Mallimaci, F. (ed.) (2008). Religión y política. Perspectivas desde América Latina y Europa. Buenos Aires: Editorial Biblos.

Mallimaci, F. y Cruz Esquivel, J. (2013). La tríada Estado, instituciones religiosas y sociedad civil en la Argentina contemporánea. Amerika, 8. Recuperado de http://journals.openedition.org/amerika/3853

Mallimaci, F., Giménez Béliveau, V., Esquivel, J. C. e Irrazábal, G. (2019) Sociedad y Religión en Movimiento. Segunda Encuesta Nacional sobre Creencias y Actitudes Religiosas en la Argentina. Informe de Investigación $N^{o}$ 25. Buenos Aires: CEIL-CONICET. Recuperado de http://www.ceil-conicet.gov.ar/wp- 
content/uploads/2019/11/ii25-2encuestacreencias.pdf [Consultado el 30 de mayo de 2021].

Mariano, R. (2005). Pentecostais e política no Brasil. Ciência e Religiąo. [En línea]. Recuperado de https://www.comciencia.br/dossies-172/reportagens/2005/05/13.shtml [Visitado el 05 de mayo de 2021].

Milsev, M. (2020). Salvación y política en el final de los tiempos. Una etnografía en la iglesia neopentecostal Misión Vida para las Naciones. (Tesis de Maestría). Facultad de Humanidades y Ciencias de la Educación, Universidad de la República, Montevideo, Uruguay.

Morlino, L. (1994). Problemas y opciones de la comparación. En G. Sartori y L. Morlino (eds.), La comparación en las ciencias sociales (pp. 13-28). Madrid: Alianza.

Mosqueira, M. (2019). Dios y rock \& roll. Cómo el evangelismo transformó el rock. Nueva Sociedad, N. ${ }^{\circ} 280,147-157$.

Mosqueira, M. y Algranti (2019). Pastor, ¿usted en qué cree? Sociología de los procesos de liderazgo e institucionalización en iglesias evangélicas de pequeña y mediana escala. Revista Cultura\&Religión, 13(1), 85-103.

Oro, A. P. (2003). A Política da Igreja Universal e seus reflexos nos campos religioso e político brasileiros. Revista Brasileira de Ciencias Sociales, 18(53). pp. $53-176$.

Oro, A. P. y Tadvald, M. (2019). Consideraciones sobre el campo evangélico brasileño. Revista Nueva Sociedad, (280), marzo-abril, 55- 67.

Oualalou, L. (2019). Los evangélicos y el hermano Bolsonaro. Nueva Sociedad, (280), 68-77. Buenos Aires, Argentina.

Panotto, N. (2020). Incidencia religiosa en clave multicultural: la presencia de redes políticas evangélicas en las asambleas de la OEA. Revista Cultura y Religión, Vol 14( $\left.\mathrm{N}^{\circ} 1\right), 100-120$.

Pérez Guadalupe, J. L. (2019). ¿Políticos evangélicos o evangélicos políticos? Los nuevos modelos de conquista política de los evangélicos. En J. L. Pérez Guadalupe y S. Grundberger (eds.), Evangélicos y poder en América Latina (2 ${ }^{\text {da }}$ ed.) (pp. 13-191). Lima: Konrad Adenauer-Instituto de Estudios Social Cristiano.

Radio Universal (14 de noviembre de 2018). La ley Trans es inconstitucional, peligrosa e injusta. Recuperado de https://970universal.com/2018/11/14/la-ley-trans-es-inconstitucionalpeligrosa-e-injusta/ [Visitada el 30 de mayo de 2021]. 
Rubin, S. (23 de junio de 2019). Poco a poco, los evangélicos comienzan a ganar espacio en las listas. Todo Noticias. Recuperado de https://tn.com.ar/opinion/poco-poco-los-evangelicos-celestes-se-abrenespacio-en-las-listas_972850 [Visitado el 23 de junio de 2020].

Semán, P. (2001). La recepción popular de la teología de la prosperidad. Scripta Ethnologica, 23, 145-162.

Semán, P. (2019). ¿Quiénes son? ¿Por qué crecen? ¿En qué creen? Pentecostalismo y política en América Latina. Nueva Sociedad, N. ${ }^{\circ}$ 280, 26-46.

Silveira Campos, L. (2005). De "políticos evangélicos" a "políticos de Cristo": la trayectoria de las acciones y mentalidad política de los evangélicos brasileños en el paso del siglo XX al siglo XXI. Ciencias Sociales y Religión, 7(7), 157-186.

Sotelo, M. V. (2020). El pentecostalismo en Uruguay y sus abordajes desde las ciencias sociales. En M. Mansilla y M. Mosqueira (eds.), Sociología del pentecostalismo en América Latina (pp. 499-544). Santiago: Ril Editores y CEIL-CONICET.

Sotelo, M. V. (2012). Religiones de ricos y de pobres. Un análisis sociológico sobre el fenómeno religioso en contextos de pobreza en el Uruguay. Saarbrücken: Editorial Académica Española.

Sotelo, M. V. (2010a). La geografía religiosa del Uruguay. Ponencia presentada en las IX Jornadas de Investigación Científica de Facultad de Ciencias Sociales, 13 al 15 de setiembre de 2010, Montevideo, Uruguay. Recuperado http://repositorio.cfe.edu.uy/bitstream/handle/123456789/796/Sotelo\%2 cM.LaGeografia.pdf?sequence=2\&isAllowed=y [Visitado el 31 de mayo de 2021].

Sotelo, M. V. (2010b). Religión y pobreza en Uruguay: algunos hallazgos cuantitativos. Revista Territorios e Fronteiras, 3(2), 270-294. Recuperado de http://repositorio.cfe.edu.uy/bitstream/handle/123456789/800/Sotelo\%2 cM.Religion.pdf?sequence=2\&isAllowed=y [Visitado el 31 de mayo de 2021].

Tilly, Ch. (1991). Grandes estructuras, procesos amplios, comparaciones enormes. Madrid: Alianza.

Wynarczyk, H. (2009) Ciudadanos de dos mundos. El movimiento evangélico en la vida pública argentina 1980-2001. Buenos Aires: UNSAM.

Arosena, F. y Sotelo, M. (2021). Desde los márgenes de la sociedad al parlamento. Evangélicos y política en Brasil, Argentina y Uruguay. Revista Cultura y Religión, 15(2), 1-38. 
Wynarczyk, H. (2019). “Argentina: ¿Vino Nuevo en Odres Viejos?”. En Evangélicos y Poder en América Latina (2da. Ed.) (pp. 193-222). Pérez Guadalupe, J.L. y Grundberger S. (eds.). Lima, Perú:.Konrad Adenauer Instituto de Estudios Social Cristiano.

Wynarczyk, H. y Oro, A. P. (2012). El pentecostalismo en América Latina. Religioni e Società, 27(73), pp. 24-31. 